\title{
Semiotic Inspection of a game for children with Down syndrome
}

\author{
André Brandão \\ Daniela G. Trevisan \\ (MediaLab-UFF) \\ Lenisa Brandão \\ (UFRGS)
}

\author{
Bruno Moreira \\ Giancarlo Nascimento \\ Pedro T. Mourão \\ (MediaLab-UFF)
}

\author{
Cristina N. Vasconcelos \\ Esteban Gonzalez Clua \\ (MediaLab-UFF) \\ Luciana Rocha Clua \\ (LIDE/PUC-Rio)
}
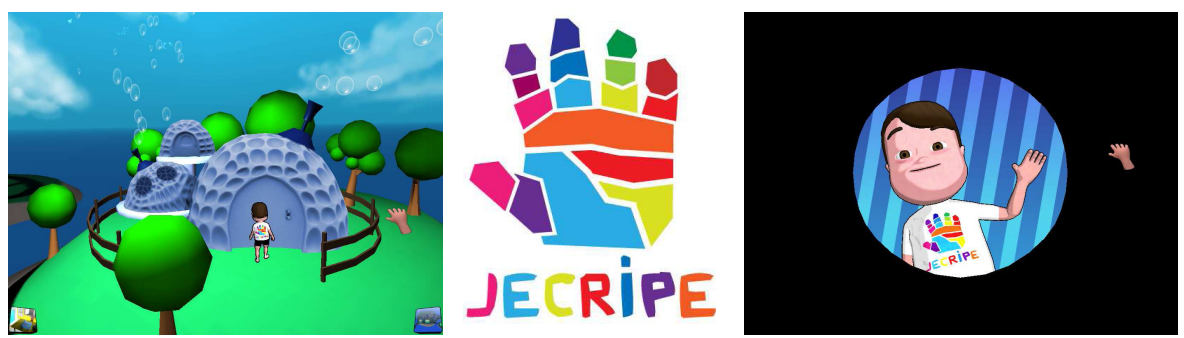

Figure 1: JECRIPE - a game for children with special needs

\begin{abstract}
Abtract
There are not many initiatives in the area of game development for children with special needs, specially children with Down syndrome. The major purpose of our research is to promote cognitive development of disabled children in the context of inclusive education. In order to do so, we address aspects of interaction, communication and game design in stimulating selected cognitive abilities. By using a Human-Computer Interaction method based on the Inspection of Evaluation, it was possible to study and understand user interaction with the interface and thus examine the positive aspects as well as the communicability problems found with the JECRIPE game - a game developed specially for children with Down syndrome in pre-scholar age.
\end{abstract}

Keywords: Down syndrome, Semiotic Inspection, Children, Communicability, Game, Human-Computer Interaction

\section{Author's Contact:}

\{andrebrandao,daniela\}@ic.uff.br

lenisa.brandao@ufrgs.br

bmoreira@ic.uff.br

giancarlotaveira@gmail.com

pedrothiago@hotmail.com

\{crisnv,esteban\}@ic.uff.br

lurocha1@gmail.com

\section{Introduction}

It is well known that digital games can provide fun for the players. For most children the first contact with the computers is through some sort of (educational) game, and children play computer games very often. Play is a decisive vehicle through which children learn about themselves, the environment, and develop social skills. However, for many children with cognitive, developmental, or physical impairments, adapted play opportunities are often limited.

Since 2008, governmental incentives in Brazil $^{1}$ have included the provision of focus to specialized educational services for students with disabilities and pervasive developmental disorders enrolled in regular public schools.

In addition, one of the five challenges proposed by Brazilian Computer Society $^{2}$ to be addressed is the participative and universal access of Brazilian citizens to knowledge.

\footnotetext{
${ }^{1}$ Decree Number 6.571, September 17th, 2008.

${ }^{2}$ Available at http://www.sbc.org.br
}

In this context, we developed the $\mathrm{JECRIPE}^{3}$ game that has a purpose of stimulate preschool children with Down syndrome. Our game stimulates these abilities through activities specifically designed for the users of our game. The following cognitive abilities are stimulated: imitation, perception, fine motor skills and hand-eye coordination and, finally, receptive and expressive verbal language.

So far, questions related to the game design aspects of this kind of interactive technology emerge during the development process. For instance how can we increase the amount of relevant information about correct stimulation of the selected cognitive abilities in addition to usability and fun problems that should be improved in games?

In the Human Computer Interaction area one of the most commonly used design philosophies to create high quality products for users is the UserCentered Design (UCD) approach [Norman and Draper 1986]. UCD refers to the philosophy that the intended user of a product should always be in the center of the design process throughout all phases of the design.

There are three types of evaluation methods: observational evaluation methods, analytical evaluation methods and inquiry methods. Evaluation methods that collect data by observing users' experiences with a product are called observational evaluation methods. These methods have a user performance view. The usability test and the user performance test are types of observational evaluation methods [Nielsen 1993]. Methods that do not collect data from users' experiences but rely on the opinion of experts are called inspection or analytical evaluation methods [Nielsen andMack 1994]. These methods have a product oriented view. Examples of analytical evaluation methods are the Heuristic Evaluation [Nielsen and Mack 1994], the Cognitive Walkthrough [Nielsen and Mack 1994] and the Semiotic Inspection [de Souza et al. 2006]. Inquiry methods focus on users' likes and dislikes, needs, and understanding of a product by asking users to answer questions verbally or in written form. These methods have a user oriented view. Inquiry methods tend to identify broad usability problems or opinions about a product as a whole. Examples of inquiry methods are User Satisfaction Questionnaires and Focus Groups [Nielsen 1993].

These methods are proper for adult users, however young children are less able to read, verbalize, concentrate, and perform abstract logical thinking than adults [Zaman and Abeele 2010]. Inquiry methods which rely on these skills are therefore not very well reliable for evaluating the user performance of young children. Furthermore, because these methods tend to identify broad usability problems or opinions about a product as a whole they are less suitable to acquire knowledge about specific problems for the purpose

\footnotetext{
${ }^{3}$ The JECRIPE game can be freely downloaded from our site at http://jecripe.wordpress.com/download and it is available only in Portuguese.
} 
of improving a product.

Many products for children are still analytically evaluated by adult experts instead of observationally because observational evaluation methods that work with adults can not always be applied with children [Hanna et al. 1997]. However, it is not easy for an adult to step into a child's world, and sometimes children show behavior with a game that is very difficult for adult experts to predict. In order to address such challenge, we demonstrate in this work how inspection methods could be well-tailored to generate valuable results in order to help designers to improve the game communicability.

Communicability is the property of software that efficiently and effectively conveys to users its underlying design intent and interactive principles. Thus, the goal of the communicability evaluation method is to let designers appreciate how well users are getting the intended messages across the interface and to identify communication breakdowns that may take place during interaction [Prates et al. 2000].

It is important to highlight our focus on formative evaluations in which the purpose of the evaluation is to detect and describe problems instead of determining general quality measures like effectiveness, efficiency, and satisfaction.

In this way, the semiotic inspection method (SIM) [de Souza et al. 2006] aims to assess how well the designer-to-user metacommunication message gets across to users through interactive systems' interfaces. Thus, it also evaluates the communicability of the software and it does not involve observing users' interaction with systems.

Recently, research on the applicability of SIM has been described in different environments. In [Oliveira et al. 2008], a study case is described in an educational environment. Peixoto et al [Peixoto et al. 2010] presented SIM in digital games and presented how the communicability of a simulation game can be improved. Their main result is a list of aspects that should be observed during the design of educational simulation games. Besides, taking the Semiotic Inspection Method (SIM) as a case, Souza et al [de Souza et al. 2010] argue that its interpretive results are objective, can be validated, and produce scientific knowledge comparable to that generated by more widely accepted methods.

The contribution of our work is twofold: development of a game to stimulate cognitive abilities for children with Down syndrome in pre-scholar age (3 to 7 years old) and evaluation of the game interface communicability.

This paper is organized in seven sections. In Section 2, we describe related work about games in health care and interaction of Down syndrome children and computer applications and communicability evaluation in games. In Section 3 we describe the Semiotic Inspection Method. In Section 4, we provide the theoretical basis for stimulating cognitive abilities. In Section 5, we present the scenarios, characters and tasks of the JECRIPE game. In Section 6, we discuss the evaluation of JECRIPE's Semiotic Inspection. Finally, in Section 7 we expose some concluding remarks and suggestions for future work.

\section{Related Work}

The use of games in health care has increased in the last years. A related experiment in this area studied the effects of a game, the Health e-Learning Network, in the effectiveness of teaching third graders in elementary schools about nutrition [Hung et al. 2009a]. The participants of this research were two classes of third graders: an experimental and a control group. The experimental group learned knowledge related to nutrition based on game playing on a National Health e-Learning Network, and the control group was lectured with multi-media slide shows. The results revealed that students from the experimental group received better scores in both a nutrition knowledge test and a dietary behavior assessment. That paper did not mention working with children with Down Syndrome.

Papastergiou [Papastergiou 2009] published an important paper reviewing the potential of computer and video games for health care.
After systematically searching online bibliographic databases, 34 relevant articles were located and included in the study [Papastergiou 2009]. This paper does not mention experiments with disabled children.

Watters et al. [Watters et al. 2006] explored the use of games for children with long-term treatment regimes, demonstrating that motivation for compliance is a key reason in the success of the treatment. Watters et al [Watters et al. 2006] presents as goals: provide easy and continual gaming access on a range of computing appliances; offer games that can be personalized and are adaptable based on the child's interests or specific illness; and keep up novelty and interest in the treatment over time. This work shows the importance of games in health-care but did not focus in children with Down Syndrome.

Another work [Goh et al. 2008] describes how a range of face-toface therapies and interventions for children and adolescents with mental health problems have been developed over the years and includes cognitive-behavioral therapy, play therapy and applied behavior analysis. This paper describes how mental health professionals have been exploring the use of games to complement traditional treatment methods. Down syndrome was not specifically considered.

Although it was difficult to find papers describing research on games for people with Down syndrome, we were able to discover some studies on this topic [Feng et al. 2008; Feng et al. 2010]. Feng et al [Feng et al. 2008] discuss the results of an online survey that investigates how children and young adults with Down syndrome use computers and computer-related devices. The survey results suggest that the majority of the children and young adults with Down syndrome can use the mouse to interact with computers, which requires spatial, cognitive, and fine motor skills that were previously believed to be quite challenging for people with Down syndrome.

Computer use by Children with Down Syndrome is described in Feng et al. [Feng et al. 2010] and presents some interesting aspects to be considered. The authors show that computers and computerrelated devices have the potential to help these children in education, career development, and independent living. However, most of the software, games, and Web sites that children with Down syndrome interact with in Feng et al. [Feng et al. 2010] are designed without consideration of their special needs, which reduces the effectiveness of the application, or even may provide a completely inaccessible application.

The topic of children interaction designs was discussed in some important events, inducing researchers to publish their work and develop knowledge about designs for children with special needs. One related paper describes a game, called CuttingGame, developed for preschool children with autism [Hung et al. 2009b]. In the proceedings of the same congress, other relevant related papers appeared [Falcao and Price 2009; Satterfield 2009]. Falcao [Falcao and Price 2009] presents aspects of tangible technologies for children with special educational needs (SEN). Satterfield [Satterfield 2009] describes the experiences of children with disabilities such as autism, epilepsy, and cerebral palsy.

As shown, the use of games in health-care is a relevant topic in research. There is a lack of studies considering Down syndrome. Thus, it is definitely time to consider the special needs in the development of applications for this population. The JECRIPE game was developed considering the characteristics of such users. In this paper, we discuss the cognitive abilities that JECRIPE aims to develop, as well as the communicability aspects of its interface contributing with a more effective insertion of Human-Computer Interaction in game research. The next section describes the cognitive abilities approached and how these are stimulated in our game.

\section{Semiotic Inspection Method}

The Semiotic Inspection Method (SIM) has been proposed within the Semiotic Engineering theoretical framework [deSouza 2005]. Semiotic Engineering perceives $\mathrm{HCI}$ as a designer to user metacommunication. It is, a twofold communicative process, because the designer to user communication is achieved through user-system 
communication. Therefore the primary purpose of SIM is to evaluate the communicability of interactive computer artifacts. As is typical of HCI inspection methods, SIM does not require an observation of users interacting with the system. Rather, the method helps inspectors ${ }^{4}$ anticipate the kinds of consequences that design choices may bring about when users interact with the system. It can be carried out by a single inspector or a group of inspectors [Prates et al. 2000].

As described by de Souza et al. [de Souza et al. 2010] SIM has a technical and a scientific application. Technical application of SIM focuses on how a method can improve and inform interaction design in the context of a specific system development; whereas scientific application focuses on how a method can broaden the knowledge of Human Computer Interaction (HCI).

Hereby we describe the SIM method according to the steps described in [de Souza et al. 2010], [de Souza et al. 2006] and [Peixoto et al. 2010]. SIM is an interpretive method through which the evaluator analyzes the message being transmitted by signs at each level: metalinguistic, static and dynamic.

Metalinguistic signs are signs that refer to other interface signs. They are instructions, tips, online help, error and informative messages, warnings and system documentation. They are signs that the designer uses to explicitly communicate to users about the meanings encoded in the systems and how they can be used. Static signs express and mean the systems state, they are motionless and persistent when no interaction is taking place. They can be perceived (and interpreted) in snapshots of the systems interface before or after interaction occurs. For instance, buttons, text areas and check boxes at a given moment. Dynamic signs express and mean the system behavior. Their representations unfold and are transformed in to responses to an interactive turn. For example, if we click on the search button the behavior will present the results of a search. This behavior is a dynamic sign [de Souza et al. 2010].

SIM is applied in five main steps:

1. The analysis of metalinguistic signs;

2. The analysis of static signs;

3. The analysis of dynamic signs;

4. A comparison of the designers metacommunication message generated in the previous steps; and

5. A final evaluation of the inspected system's communicability.

The first three steps are iteratively carried out, and the last two steps can be carried out in one pass each. Like other inspection methods, SIM requires a preparation step. Preparation is carried out in four sub-steps. First, the inspector defines the purpose of the inspection, given the specific context where the method is being used. In scientific contexts, researchers must choose an application instance that serves the purpose of investigation. In technical contexts the application is given. The second step is to do an informal inspection of the system in order to define the intended focus of the evaluation. The analyst reads summarized project documentation or promotional material associated with the object of inspection (websites, information on the product's package, quick guides, and the like). The third step is to navigate through the system, tracing evidence to confirm the intended users of the system and the top-level goals and activities that the system supports. Finally, in the fourth step, knowing the purpose of the analysis, the interlocutors involved in communication, which contexts are significant, and which types of effects communication should achieve, the inspector elaborates inspection scenarios that provide the necessary contextual structure required for analyzing communication [de Souza et al. 2010].

Basically scenarios identify the person as having certain motivations toward the system, describes the actions taken and some reasons why these actions were taken and characterizes the results in terms of the users motivations and expectations [Carrol 1997]. Then scenarios explicitly and implicitly indicate the context of the action,

${ }^{4}$ Inspector or evaluator is a person with experience in performing $\mathrm{HCI}$ evaluations.

IX SBGames - Florianópolis - SC, November 8th-10th, 2010 and have a central character (the inspector, playing the role of the user) that performs the action implied by the narrative [Peixoto et al. 2010].

In technical contexts of use, the first preparation step typically involves conversations with its designers and developers. Talking to other stakeholders, like the system's owners and members of the user population, will give the inspector additional interpretive clues to be used in the core steps of the method. In scientific contexts of use, however, where the main purpose of inspection is typically to identify and explore HCI research issues, talking to the various stakeholders may be more useful for triangulating SIM results. Instead, the first preparation step should produce a clear statement of research goals, as well as a careful examination of how SIM results can contribute in achieving them. The other three preparation steps are the same in both technical and scientific contexts of use [de Souza et al. 2010].

After preparation, the five core steps of the method are executed. The first three of these steps correspond to a segmented analysis of signs. Each step focuses on a single class of signs (metalinguistic, static, and dynamic). These steps are also iterative because given the very wide spectrum of possible interactions that systems usually enable, inspectors are likely to encounter in core step 3 (while analyzing dynamic signs) metalinguistic or static signs that escaped him in previous steps. This will make them to go back to core step 1 or 2 to revise his findings in those steps [de Souza et al. 2010].

The goal of step 4 is to collect and compare the results of segmented metacommunication analysis. This is one of the key steps of the method because in it the analyst can capture important elements for the final step of analysis. First, the analyst must look for communication conveyed by one class of signs that is contradicted by communication conveyed by another. Second, the analyst must detect if gaps in the instantiated template at the end of one step are filled out by meanings represented in the instantiated template of another step. If they are not, the emission of metacommunication is incomplete by design, and the analyst must investigate what effects are achieved by such incompleteness. Third, the analyst must examine the distribution of metacommunication message components across sign classes. Message components appearing in all three templates of segmented analysis achieve redundancy and mutual reinforcement in communication. Message components appearing in a single template rely heavily on the users ability to identify and interpret the corresponding class of signs appropriately [de Souza et al. 2010].

Communicability of the system is evaluated in step 5. This step allows the analyst to assess the adequacy, the costs and the benefits of communicative characteristics, and the strategies identified in previous steps. This is the time to evaluate the effects of inconsistencies, gaps, and lack of redundancy in metacommunication, if found in step 4. It is also the time to detect the adequacy of communicative strategies for special domains of application, special technologies, and special user populations, for instance. In professional practice and technical contexts of application, this characteristic of the method is an important asset, because it continually expands the competence of the analyst. New analytic dimensions, opportunities, challenges, effects, elements, and contextual factors involved in the semiotic engineering of humancomputer interaction are constantly added to the analyst's stock of knowledge [de Souza et al. 2010; Peixoto et al. 2010].

However in order to validate such knowledge Souza et al. [de Souza et al. 2010] suggest to adopt validation procedures and criteria used by qualitative research methods in general and proceed to a triangulation of results. The goal in triangulation is to promote diversity in the conditions of knowledge discovery and to expose our findings to contradiction. Commonly used diversification techniques include: having different analysts use the same method and contrast their results; using different methods to analyze the same data; and invoking different theories to explain (aspects of) the findings. Findings are validated when triangulation procedures generate consistent (although diverse) knowledge. When inconsistent interpretations are found, interpretation processes start again. In other words, self-correction takes place as part of ongoing abductions. New hypotheses are formulated and the analyst engages in a new 


\section{Cognitive abilities stimulated by the game}

Much attention has been directed toward identifying special needs associated with Down syndrome in speech-language pathology and psychology research. Researchers have been able to show patterns of behavioral characteristics including strengths in the areas of social functioning and weaknesses in such areas as language, shortterm memory, imitation, perception, visual-motor skills and other cognitive functions [Feeley and Jones 2008]. This knowledge, combined with studies demonstrating effective intervention strategies, contributes to the advance of computer based cognitive interventions for the development of people with Down syndrome.

\subsection{Imitation}

The development of imitation skills is highly associated with language development. Studies have shown that to learn language, children must be able to imitate. In the early stages of language learning, children will imitate adult speech. Therefore, language interventions should consider the stimulation of imitation. This ability has an important impact in the development of socialization skills, because through imitation, children learn how to behave, cooperate and react [Schopler et al. 1990]. Children with Down syndrome show significant deficits in imitation skills when compared with those with typical development [Nielsen and Hudry 2010; Somogyi et al. 2006]. Their imitations are poorer and more restricted. However, they show better performance in imitation than in expressive verbal language tasks [López and Nuevas 1997; So and Dodd 1994].

Smith [Smith 1987] showed that children with Down syndrome have a tendency to favor gesture and use non verbal speech acts in detriment of verbal expression. Most of them understand messages, and are able to produce language (through signs) well before they are able to use speech. However, they seem to avoid the combination of vocalization and gesture schemes. Imitation can contribute effectively for the development of verbal behavior in children with developmental disorders. Learning to imitate sounds and words is critical in the quest to become verbal. Imitation facilitates lexical, grammatical and conversational skills development [Hwang and Windsor 1999]. Teaching a child to imitate words often begins with teaching how to imitate. Starting with movements of the body than with words can be an effective strategy.

Latash [Latash 2000] suggested that over time, people with Down syndrome can learn how to develop adaptive motor strategies that optimize safety and stability. This author suggests that early intervention should focus in the exploration of a range of motor solutions to avoid the development of fixed patterns of motor behavior. Modeling easy movements, such as clapping and waving bye-bye during interactive songs such as a Peek-a-Boo is a commendable task [Tristao and Feitosa 1998]. In addition, Bird et al. [Bird et al. 2000] discussed evidence for the facilitation effect of signs and the advantage of dual-method (signing and producing words) as an intervention technique for this population.

The finding that children with Down syndrome can accurately reproduce rhythmic stimulus [Pickard 2009] shows that allying music to cognitive interventions can be a rewarding form of stimulation. Musical activities are very beneficial to children with Down syndrome because they learn best with activities that are repetitive and engaging. Music is fun for most people and will help a child to pay attention. The rhythms and repetitiveness of music help children with Down syndrome remember gestures and lyrics more easily and music fits perfectly in imitation tasks.

The findings mentioned in this section inspired the imitation tasks created for JECRIPE in a virtual place named The Music House. In this house the game demands the imitation of simple movements of the body, accompanied by singing interactive popular songs demonstrated by the software. The details of The Music House created to stimulate the imitation ability is described in Section 5.2.
According to Schopler et al. [Schopler et al. 1990], auditory and visual perception, serve as the main basis for mental selection and organization of stimuli. Relatively little research has examined the perceptual abilities of children with Down syndrome. The speed of sensory discrimination is affected in this population. They need longer periods of time to react to stimuli and present a greater frequency of wrong answers as a response to perceptual tasks [Rondal and Lambert 1983].

Children with Down syndrome are able to make basic perceptual discriminations but show impairments in the perception of complex visual motion cues [Virji-Babul et al. 2006]. Substantial deficit in perception of optic-flow motion has been shown in the performance of Down syndrome participants [Viva and Cioni 2004]. Additionally, infants show differences in attending to and processing information early in their development. For example, they engage in much fewer referring to looks (i.e., pointing, eye-gazing, and joint attending) that guide attention and action [Kasari et al. 1995]. According to López and Nuevas [López and Nuevas 1997], children with Down syndrome tend to focus more on details than on the visual stimuli and this impairs their performance in visual discrimination tasks.

Considering the importance of the exposition of those children during pre-scholar age to auditory and visual stimuli to overcome limitations in perceptual processes, a scenario was created in JECRIPE, named The Bubbles House, that exercises the well-functioning of visual and auditory modalities, guided by different sounds. In this scenario, animated bubbles should be popped by the user, and colored toys should be matched to corresponding colored boxes. The details of The Bubbles House created to stimulate the perception is described in Section 5.3.

\subsection{Fine motor skills and hand-eye coordination}

Human interaction with the environment is mostly done through movement. Action is essential to the development of language and cognition [Schwartzman 1999]. Autonomy and independence in activities of daily living depend heavily in the development of fine motor skills [Schopler et al. 1990]. Hypotonic muscles and alterations in the articulations contribute to the delay in the development of movement control and motor acquisitions. These factors contribute to reduce the strength of manual grasping of children with Down syndrome, making it difficult to manipulate objects. Cerebellar dysfunction also interferes considerably in the regulation of motor activity. Additionally, children with Down syndrome have difficulties in integrating visual and proprioceptive information.

Consequently, hand-eye coordination is impaired. There is already some evidence in the literature that children with Down syndrome demonstrate impairments in perceptual-motor coupling. For example, when they perform motor tasks requiring anticipatory actions (such as catching), their impairments seem to be attributable to difficulties in regulating the temporal aspects of their actions [Savelsbergh et al. 2000]. Charlton et al. [Charlton et al. 2000] reported that these children have difficulty in properly adjusting both the spatial and temporal aspects of their grasp as a function of object size or task goal. They manipulate toys less often and tend to hold them, showing more passive behavior. These early difficulties in manipulating toys may significantly impair the child's ability to actively explore and make sense of their environment and impede the learning process of extracting salient information, in both social and physical contexts [Landry and Chapieski 1989]. Additionally, the development of writing skills relies in the competence of these functions.

A virtual place in the JECRIPE game was created considering specifically the stimulation of fine motor skills and hand-eye coordination, named The Day Care Center (although it is also exercised in the Bubbles' House scenario). Playing with the Day Care Center the child manipulates the mouse to drag-and-drop objects to deliver personal objects to a baby character. The details of the Day Care Center are described in Section 5.4 while the Bubbles' House scenario is detailed in 5.3. 


\subsection{Receptive and expressive verbal language}

Studies about the development of children with Down syndrome draw attention to the delays to be expected in their speech and language development. Despite individual differences, these children are usually late in saying their first words, their vocabulary grows more slowly and, although they use the same range of two-word phrases as all children, they have difficulty in producing grammatically correct sentences [Buckley 1993; Buckley 1994]. Many of these children have more difficulty with expressive language than they do with understanding language. Therefore, receptive language skills are usually more advanced than expressive language skills.

Difficulties with learning to talk adequately has several consequences for children's development. Language enables a child to communicate in more effective and complex ways, to gain increasing information about the world and to organize mental processes such as thought and memory. Language enables us to have control over our lives. Through language, we can ask for what we want or need, tell people how we feel, share our joy and our worries, make friends, develop a social life. If children with Down syndrome develop only limited ability to talk, they will be more isolated from other children and their social and emotional lives will be impoverished.

Pragmatic language skills are stimulated by JECRIPE through requests and greetings, as well as rewarding and encouraging affirmations, in all three developed environments (the Music House, the Bubbles House and the Day Care Center). All the game tasks are planned to increase auditory attending. The vocabulary skills are stimulated by reinforcing affirmations of the voice which interacts with the player in JECRIPE, by giving instructions.

Some of the activities dealing specifically with receptive and expressive verbal language in each scenario are showed in the following examples. In the Music house, receptive language skills are stimulated by activities which include pointing at body parts according to musical lyrics. In the Bubbles House the child has its perception stimulated while recognizing objects and colors. Last, in the Day Care Center, interpreting non verbal requests of a baby with Down syndrome is the main task.

\subsection{How JECRIPE stimulates cognitive skills}

As described, the main character called "Betinho" which is a boy with Down syndrome interacts with the player in JECRIPE to stimulate cognitive, pre-language and language skills. The game provides three main settings: the Music's House, the Bubbles' House and the Day Care Center. As the player progresses in the game, different tasks are proposed. The ability to imitate speech and gestures is stimulated in a singing and gesture task at the Music's House. Visual and auditory skills are developed by looking at objects and listening to instructions, feedback and music at the Bubbles' House. Fine motor skills, eye-hand coordination and other abilities such as short-term memory are exercised by understanding object permanence, cause and effect relationships at all settings. Non verbal language and verbal language skills are stimulated in the Day Care Center setting, as the player is asked to give the baby with the objects he asks for.

The voice in the game talks often to the player, telling the child about things and giving choices. The voice provides feedback in a positive, supportive, playful and caring way. It is our belief that interventions using computer games such as JECRIPE can be used with Down syndrome children to stimulate language and cognitive skills and promote the improvement of quality of life.

Nevertheless all the theoretical basis that make possible reach our goal (stimulate cognitive areas using our game) need to be developed somehow. The next section describes some important issues about JECRIPE's development.

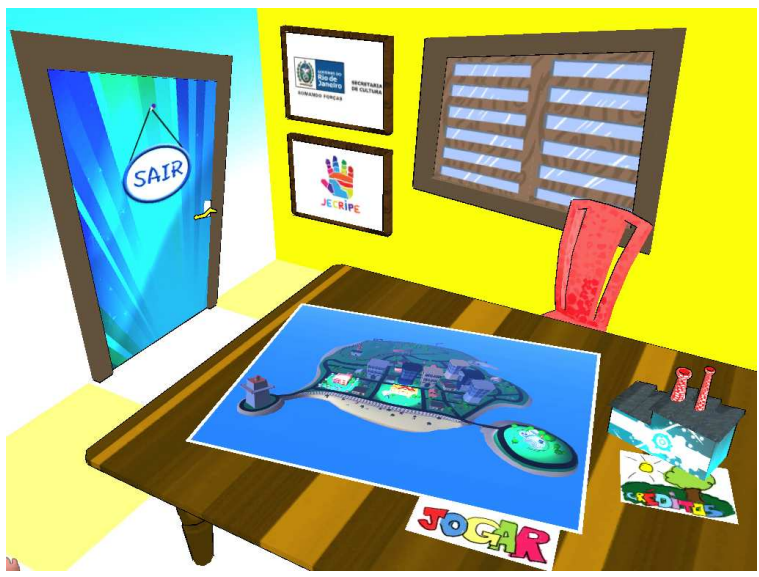

Figure 2: The introductory scenario.

\section{Design of activities for stimulation of the selected cognitive areas}

Effective technology per se provide only the enabling condition for creating a learning experience. What makes it useful and engaging is, obviously, how users work with technology. The true challenge is to design appropriate contents and tasks that meet children's needs and educators' goals. In the present study, this experience design work involved all disability experts who participated in the contextual study, speech-language pathologists and the research group from our lab.

The JECRIPE game has different scenarios, each one elaborated to stimulate the cognitive abilities described above. Next section presents all the scenarios of the game. Before starting to play, the user has to interact with an introductory scenario.

\subsection{The introductory scenario}

The introductory scenario is where the user decides if he wants to start playing, to view the credits or to exit the game. It is illustrated in Figure 2. This scenario represents the learning environment where the child starts interacting with our playful stimulating game. It is composed by a table and a door. On the table, there is a map and a little factory. To start playing, the user needs to click on the map that illustrates JECRIPE's Island. Following the click, the system loads the Island scenario (called the JECRIPE Island, Figure 3 ) where activities are located. The user can see the three buildings that represent our different tasks: the Music House, the Bubbles House and the Day Care Center. When each building is clicked, Betinho conduces the child into the House, where the chosen task starts.

Back to the introductory scenario, if the user clicks on the little factory, the game credits are shown in a Credits Scene where Betinho runs and the name of each member of our team appears on some clouds. To exit the game, the door must be clicked, a Good bye Scene is shown and the main character reminds the player about the activities that took place in the island (according to records registering his last play). Finally, after the Good bye scene, the application shuts down.

The next subsections describe all three interactive houses where the cognitive abilities are stimulated.

\subsection{The Music House}

The Music House, aims at stimulating fine motor skills and handeye coordination ability, the player is induced to click twice on the doorbell, by an instruction voice. Once the task is completed, the camera is positioned so that the player can then see the front of the house with six windows. Each window is associated with a different simple choreography and correspondent song.

The user chooses a window using a single click. After that, the win- 


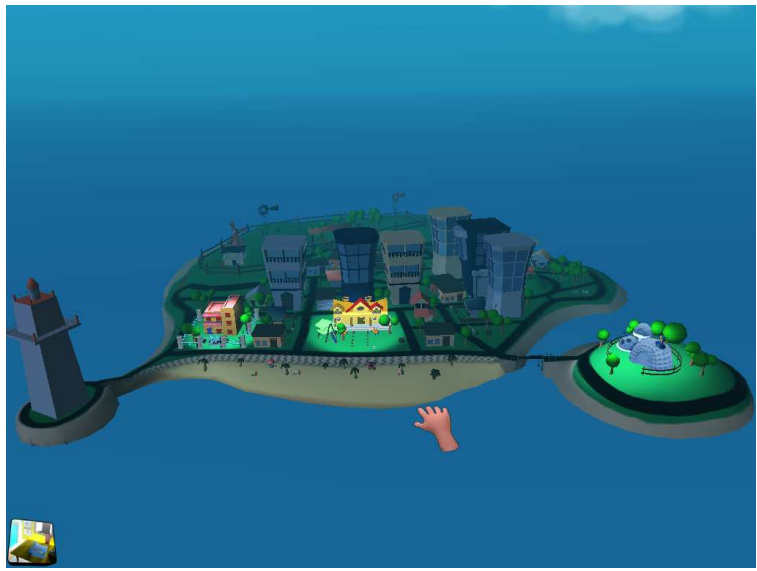

Figure 3: JECRIPE Island.

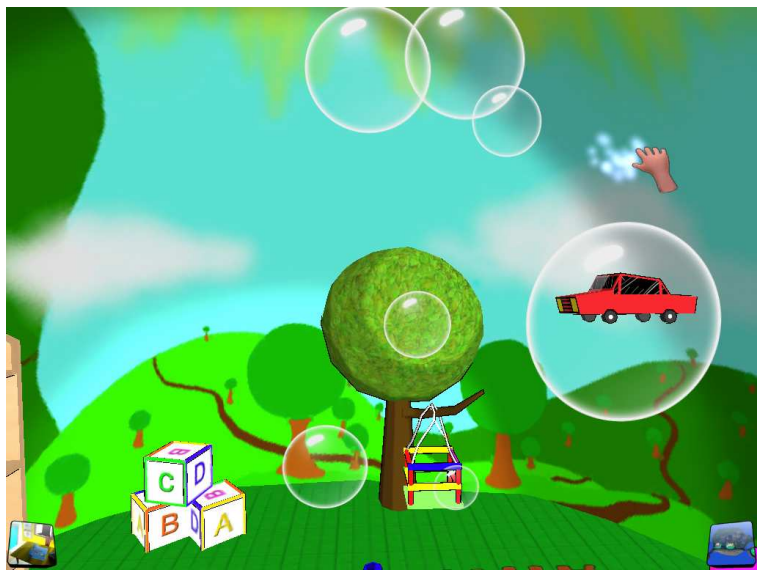

Figure 5: Bubbles' House: Some bubbles have toys in them. dow opens and Betinho appears and starts to dance. Then, in order to stimulate the imitation ability, the player is induced to dance with him. Receptive and expressive verbal language is exercised because the child has to pay attention in the instructions and interact with the game. All the songs were selected from Brazilian popular culture. Figure 4 illustrates Betinho dancing. After the song is played, the window is closed and the user is conducted to his or her original position, in front of the house. The player can dance each song as many times as he/she wishes, until all the dancing windows are visited.

As mentioned before, the Music House stimulates the abilities of imitation, receptive and expressive verbal language, fine motor skills and hand-eye coordination. The next subsection describes the Bubble House.

\subsection{The Bubble House}

The Bubble House activity contains three sub-tasks designed to stimulate the perception abilities. In order to prepare recipe for making bubbles, the player has to mix a set of ingredients correctly and move them into a recipient. The first ingredient is a water bottle, followed by a soap bottle and a cover cap.

A second task was developed to stimulate fine motor skills and hand-eye coordination ability. An instruction voice induces the player to pop floating bubbles. Some of those bubbles have colored toys inside them (Figure 5). When a bubble is popped, the respective toy falls down to the ground. The condition to complete this task is to pop all the bubbles that contains a colored toy.

A new task starts where the player is invited by the instruction voice to put the toys inside boxes according to matching colors. Once all the toys are placed in their respective boxes, a congratulation and

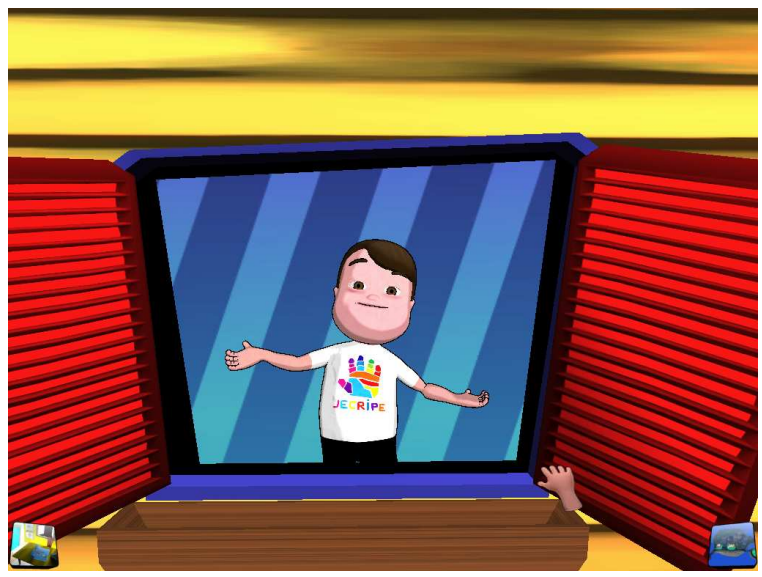

Figure 4: The Music House: Betinho is dancing while a song is played inside the house. farewell voice greets the user.

In all these sub-tasks, the player uses the mouse only by moving it (without clicking). The game constantly rewards each accomplished sub-task with positive reinforcement sentences. By the time the player finishes all the activities of the Bubble House he/she has exercised perception, receptive and expressive verbal language, fine motor skills and hand-eye coordination abilities.

After that, the Island scene is loaded again and the player is ready to choose his next activity.

\subsection{The Day Care Center}

This scenario was chosen as favorite to the children that have already played JECRIPE under our observation. Its activity explores the drag-and-drop capabilities, stimulating fine motor skills and hand-eye coordination together with receptive and expressive verbal language.

Inside the Day Care Center, there is a baby sitting in a chair and there are four objects placed on top of the shelves (a rattle, a soup plate, a pacifier and a baby bottle). The four objects and the baby are illustrated in Figure 6. The baby is called Samuca and, as Betinho, he has Down Syndrome. Samuca does not know how to talk, but he asks for what he wants by pointing at the desired object. The baby character is animated by turning his body and face directly to the object, indicating the universal gesture: "the baby wants that object".

When a player clicks on an object which is not the one that the baby wishes, he manifests dissatisfaction. Then, an instructional voice indicates the desired object and the baby faces that specific object again until the user grants his wish. Once the correct object is clicked, it moves with the mouse cursor while it is being pressed.

When the mouse button is released, the position of the dropped object is checked. If the object is released in any other place then the babys body region, the object is moved back to the original place on top of the shelf.

After all the objects have been delivered to the baby, he starts clapping his hands and a success audio clip is played announcing the end of the activity. As described, in this house the player stimulates receptive and expressive verbal language as well as fine motor skills and hand-eye coordination.

\subsection{Technical issues}

This section briefly presents the Unity3D engine with the goal of providing the reader a view of the engine features used during the development of JECRIPE game. Unity3D is a game engine that supports the development of 3D games [Technologies 2009].

Unity3D works with the concept of Game Objects, that works as a repository of functionalities, or more specifically, Components, following Component Oriented Programming methodology. Each ele- 


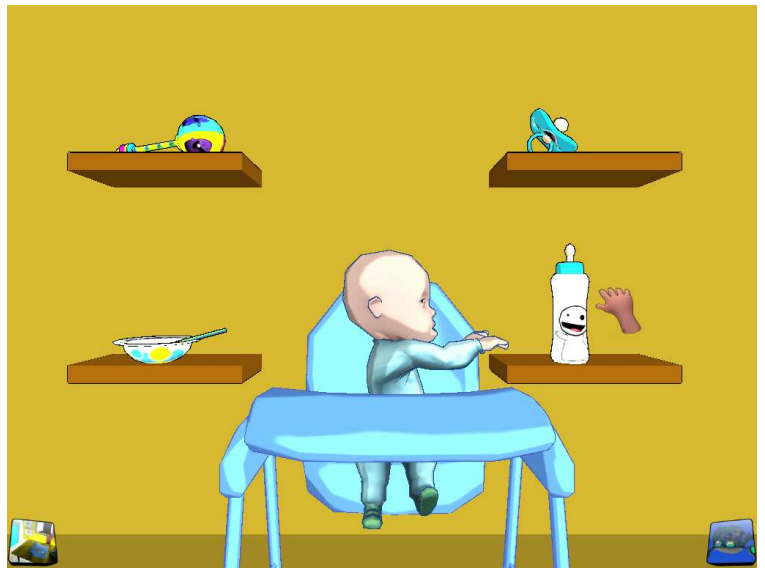

Figure 6: The Day Care Center: The objects on the shelves and the baby with Down syndrome.

ment inside a scene is a Game Object (a script, a collision geometry algorithm, or even a GUI Texture). They are specified through compositions of parts and features, associating functionalities, which are added (or removed). The functionalities are implemented by components (class that inherits from a basic component) that are responsible for implementing the many behaviors that a Game Object can have.

Thus, the Game Objects can represent everything in the scenario from a simple camera to a complex character, being different only by the set of Components that are attached to each one.

JECRIPE's development was done through the creation of a scene for each different activity, where the cognitive abilities stimulation takes place. Through Unity3D it was possible to develop each scene in a total independent way. This property of the engine made it possible to assign different tasks to each of our team members.

\section{Evaluation of JECRIPE's Semiotic In- spection}

Now we start describing the steps of the inspection method applied to the JECRIPE game. We perform a technical application of SIM in order to evaluate the communicability of a game for children with special needs, specifically regarding its feedback.

\subsection{Preparation}

As mentioned in Section 3, in the Semiotic Inspection Method there is a sub-step called Preparation. We elaborated a scenario for JECRIPE evaluation. This inspection scenario describes a child with specific characteristics and she will play the JECRIPE game as part of a therapy stimulation with a speech therapist.

In order to provide the inspector with additional interpretive clues to be used in the core steps of the method the preparation phase was performed through coupled interaction with game designers and the involved speech therapist. The inspector performed some remote interviewers with the therapist and was possible to follow one session of the game use in a inclusive school.

Larissa is five year old child with Down syndrome. She has been stimulated in a speech-language clinic in the last six months with physical activities involving: dancing and singing musics, popping bubbles, color and object recognition, among others. These activities stimulate different cognitive areas: imitation, perception, fine motor skills and hand-eye coordination and, finally, receptive and expressive verbal language. The duration of each therapeutic encounter is one hour per week. Larissa's computer experience is limited to using a few digital games in the last eight weeks. The first digital games Larissa used were not developed for children with special needs. As a consequence, many interruptions had to be done because it was necessary to use different activities in different games for the stimulation of her cognitive abilities. Last week,
Larissa's speech-therapist was informed about the JECRIPE game, a software developed for the stimulation of the mentioned cognitive abilities for children with Down syndrome in pre-scholar age and she decided to use this game for testing it and reporting results. She hopes that the JECRIPE game can be a good choice for stimulating children with Down syndrome in a proper way and to solve the interruption problem. At first, JECRIPE needs to be assisted by the child's parents or a speech-therapist because the player has to make a double click for initializing the game and sometimes the child does not have the fine motor skills to do that. Another reason for using JECRIPE assisted by an adult is to monitor the development of the cognitive abilities. The speech therapist accessed the JECRIPE web-link and downloaded the game. At home, Larissa has a personal computer and she can play digital games according to the availability of her parents and her willingness. Now, Larissa is going to start using JECRIPE for the first time.

In our scenario, Larissa is the central character and she will be induced to use our game. The selected cognitive abilities will be stimulated through our application and the goal of the inspection is to evaluate how feedback is communicated to JECRIPE's players, e.g. how is JECRIPE's communicability. In a broaden context the goal of this analysis is to identify feedback issues on educational games for children with down syndrome. We will evaluate two kinds of feedbacks provided by the game: instructional feedback and informative feedback. Instructional feedback informs players how they should to interact with each activity proposed. Informative feedback presents information regarding the effects of the players action on the game and it aims at maintaining players curiosity and interest in the game. Mainly it refers to errors and congratulations messages.

\subsection{Step 1 - Analysis of metalinguistic signs}

As mentioned before, the goal of metalinguistic signs analysis is to identify important elements used in the designers' discourse. The metalinguistic signs are used to provide a better understanding of the static and dynamic signs as well as the relation among them.

As JECRIPE has no manual tutorial or help available, to analyze the metalinguistic signs the downloading site, dialogs, messages were inspected in regard to what designers intend to communicate to players focusing on feedback.

As a template result we can summarize this step in the following messages, where "we" means "we, the designers" and "you" means "you, user, or in this case, Larissa, the player":

a) You can hear the audio instructions provided to you to know what to do. In the Day Care Center you can hear and see Samuca's movements and decide what you should do.

b) You can hear instructions again if you stay for 5 seconds without interacting correctly with the game.

c) In the Day Care Center you can perceive the feedback (positive or negative) about your action through audio and movements emitted by the Samuca character.

d) In the Bubble house you can perceive the feedback about your positive action through audio messages such as: "Look, you hit the bubble".

e) In the Music house you can perceive the feedback only at the end of activity.

f) You can see which houses are available to play through illumination over them.

g) Before you leave the game you receive a feedback about which houses you have played. In case you have not played in any of the houses, you will hear a message inviting you to go back and play.

h) If you want to obtain more information about the game functionalities, you should ask for the adult responsible which is following you. 


\subsection{Step 2 - Analysis of static signs}

During the analysis of the static signs, important signs were identified with regard to the feedback messages.

a) We provide a playful introductory environment and you can notice that you are in a room with a door a window and a table. On the table there is a map and a factory (Figure 2).

b) We provide a playful interactive environment called the Bubble House and you can notice that you are in a room with a door, a window and a table. On the table there are a map and a factory (Figure 5).

c) We provide a ludic interactive environment called the Day care Center and you can notice that you are in room with a door a window and a table. On the table there are a map and a factory (Figure 6).

d) We provide a ludic interactive environment called the Musics' House and you can notice that you are in room with a door a window and a table. On the table there are a map and a factory (Figure 4).

e) We provide audio instructions adapted to activities of each interactive environment.

f) We provide a mouse pointer using a child's hand metaphor with Down syndrome appearance.

g) We consider that you will be able to infer that the lighted houses (as shown in Figure 3) can be selected by clicking on it.

h) We consider that you will be able to infer the following mouse interaction forms: just moving the mouse in the Bubble House and dragging-and-dropping the mouse in the Day Care Center.

e) In the Music House, we expected that you will be able to infer that you should follow Betinho's movements.

\subsection{Step 3 - Analysis of dynamic signs}

During the analysis of the dynamic signs, the essence of what JECRIPE designers intend to communicate to the players can be understood as the system behavior. Then, the feedback system behavior can be summarized in:

a) We use various metaphors of playful environments to determine the activities and interactions you may have with the game.

b) We consider that you have some previous knowledge about computer-based usage.

c) We expect you start playing immediately after listening the first instruction.

d) During the game interactions in the Day Care Center and in the Bubble House you can listen to messages related to the results of your actions.

e) During the game interactions you can see information (e.g. Samuca baby's animations) related to the results of your actions.

f) While performing mouse-based interactions you can visually infer when the mouse is pressed and released through the hand animations (e.g. metaphor for the mouse pointer).

\subsection{Step 4 - Collate and compare}

After performing the above analysis, we can conclude that the metalinguistic signs are important keys for the success of JECRIPE game once they assist the players actions continuously over time. The metalinguistic signs motivate players in this game by providing them with the necessary information to better understand what they should do.

By comparing the analysis presented in steps 1,2 and 3 we observe that in no moment the players are informed that they must have previous knowledge about computer-based interactions. Another contradictory or missing information regarding the intention of designers and what they are transmitting through the JECRIPE interface is the fact that players should be assisted by an adult. Additionally, there are no signs informing the player how he/she should use mouse-based interactions in each environment.

Although we did not find a physical static sign to represent the instructional metalinguistic sign, this should not be considered as a contradictory or missing design aspect, because the player is receiving the right message just at the time it is needed. Also we observed there is no static sign to represent informative feedbacks in two of the houses. In the Day Care Center visual and audio feedback are used to inform positive and error responses related to the player actions. In the Bubble House only positive messages are transmitted to the player while she/he is interacting with the game. On the other hand in the Music House no feedback is transmitted during the player actions, only at the end of the interaction a graceful message of participation is emitted independently of the players actions.

Also we noticed that the player can change the order to visit the selected activities independently of its difficulty level. We also observed that different kinds of informative feedbacks were being used along the houses.

It is important to remember here that the inspection analysis was mainly focused on the feedback aspects of JECRIPE interface. Others signs, for instance, those related to the interface navigation, could also be analyzed in further evaluation.

\subsection{Step 5 - Evaluation results}

Despite the fact that metalinguistic signs are providing the correct feedback with regarding player interaction, these feedbacks are not achieving the goal of stimulating the learning process, at least not in the expected way. In the Day Care Center the player demonstrates satisfaction (by laughing) when repeating the error, produced just to see and to listen to baby Samuca's dissatisfaction animation again. This fact demonstrates the user is enjoying the game, however it was important to recognize the fact that JECRIPE does not have a global goal in order to motivate the player's advance with the game. All the interactive houses present only a local goal not interfering in the other houses or activities. Addressing such challenge, proper communicability signs could be inserted into the JECRIPE interface in order to transmit this message to the player. For instance, the game could start with a short narrative presenting the goal of the game: "The goal of the game is to help Betinho become happy. According to the activities you perform in the houses you can see how the expression in Betinho's face are changing. Let's make Betinho happy." The communicability static sign for this metallingustic sign could be a small window displayed along the all interactive houses showing Betinho's face expressions.

Another missing sign found along the analysis of these tree steps is related to the mouse-based interactions. In the Bubble House the player does not need to press mouse buttons to play, but this information is not communicate to the player in any moment. The same occurs in the Day Care Center where the player needs to drag-anddrop the mouse to play but this information is not communicated in any moment. Designers hope that the player will be able to deduce it based on the player's experience in using computers.

In order to support players without previous knowledge about computer based usage the audio informative feedback could include instruction of how the player may apply the mouse in each environment. Furthermore, an attempt to support several kinds of user knowledge, the game could provide the possibility of configuring such option according to the player's experience (e.g. novice or not).

\subsection{Triangulation}

Although triangulation step in the technical application of SIM is optional we have chosen to perform this step in order to verify some evidences through observations with real users.

We observed an user as a deputy of our profile (children with Down syndrome) and we made some considerations: 
- The Musics House: the player can not imitate all the movements suggested by the character because the amount and complexity of these movements are very hard for children with disabilities. Also, the lyrics of the songs do not induce the players to dance correctly and one as a consequence, sometimes, the player would stand still.

- Bubble House: in this house, the user does not have to make a mouse click to execute the activities but the observed player use to click because she knows how that device works.

- Day Care Center: it was possible to observe that the knowledge of how the mouse works was used very well in the dragand-drop activity.

Comments made by other people related to players of the JECRIPE game (children with Down syndrome) were found. Some of them are:

- We observed comments in some home pages made by parents of a child with Down syndrome that their son played the game and the mouse pointer is appropriate and facilitates the user's interaction.

- Educators commented in the Internet that it was a good idea making Betinho conducting the player into the houses.

- An user of a Social Network mentioned that he's son has Down syndrome in pre-scholar age and when he plays the JECRIPE game makes him positively excited.

- The mother of our deputy user considered that the game provides more interaction between the child and her parents.

Besides these feedbacks, an inclusive school has provided the use of JECRIPE and observed that the application facilitated socialization between the students with Down syndrome and the others without special needs. Also, the game promoted positive socialization experiences between children with other kinds of special needs. A child with autism had fun with the other children by playing with JECRIPE.

\section{Conclusions and future work}

In this work, we presented a game for children with Down syndrome in pre-scholar age called JECRIPE. Our game was especially developed for these kind of users but children that do not have special needs can play with JECRIPE too. As mentioned by UN$\mathrm{ESCO}^{5}$, "When inclusive education is fully embraced, we abandon the idea that children have to become normal in order to contribute to the world... We begin to look beyond typical ways of becoming valued members of the community, and in doing so, begin to realize the achievable goal of providing all children with an authentic sense of belonging."

Another contribution was applying the Semiotic Inspection Method in the JECRIPE game. By performing the inspection evaluation it was possible to observe mainly positive aspects of the JECRIPE interface. However with additional observation of game usage, it was possible to increase the evaluation. Looking for improvements in the learning process, the JECRIPE game could provide the possibility of controlling the access order of each house as well as to have a major goal guiding the interactions trough the houses. Of course such suggestions should be discussed and validated with the specialized multidisciplinary group (therapists, educators, children's parents) involved in the JECRIPE development process.

Another conclusion is the application of the SIM improved when we observed a deputy that represents the profile of the game public. In our case, we observed a five year old child with the characteristics mentioned in the Preparation phase of the Semiotic Inspection Method. The reactions of that child was important because none of the developers of the JECRIPE game has Down syndrome and without an observation in the users deputy, it would be more difficult to identify the problems in our game.

\footnotetext{
${ }^{5}$ Inclusive Education: The Way to the Future. Available at http://www.ibe.unesco.org/National_Reports/ICE_2008/brazil_NR08.pdf
}

Finally this work identified feedback aspects and relevant issues not only to the system evaluated, but for all kinds of games for children with special needs used in educational contexts. We expect to make more activities in the JECRIPE game, and using the results of the application of the SIM, we will make the improvements in our software. Further, we intend to perform the application of the Communicability Evaluation Method [Prates et al. 2000]in JECRIPE to observe more users playing the game.

\section{Acknowledgments}

Special thanks to CAPES for the scholarship of the first author of this work and Secretariat of Culture of the State of Rio de Janeiro for sponsoring this project. The MediaLab/UFF Team for assisting in this study and for the inspiring and fruitful cooperation. Also thanks to Fernando Ribeiro and Anna Carollina Cotta who also participated in the characters and environments design and a special thank to Silvia Brandão, one of our speech therapists.

\section{References}

Bird, S., Buneman, P., AND TAN, W. C. 2000. Towards a query language for annotation graphs. In Proceedings of the Second International Conference on Language Resources and Evaluation, ELRA, 807-814.

BUCKLEY, S. J. 1993. Language development in children with down syndrome - reasons for optimism. Down Syndrome Research And Practice 1, 1, 3-9.

BUCKLEY, S. J. 1994. The language development of children with down syndrome: First words to two-word phrases. Down Syndrome Research And Practice 2, 2, 71-75.

CARrol, J. M. 1997. Scenario-based design. In Handbook of human-computer interaction, Elsevier Science, 383-406.

Charlton, J., IbSen, E., AND Lavelle, B. M. 2000. Control of manual skills in children with down syndrome. In PerceptualMotor Behavior in Down Syndrome, Human Kinetics, 25-48.

de Souza, C. S., Leitao, C. F., Prates, R. O., and da Silva, E. J. 2006. The semiotic inspection method. In IHC '06: Proceedings of VII Brazilian symposium on Human factors in computing systems, ACM, New York, NY, USA, 148-157.

de Souza, C. S., Leito, C. F., Prates, R. O., Bim, S. A., AND DA SILVA, E. J. 2010. Can inspection methods generate valid new knowledge in hci? the case of semiotic inspection. International Journal of Human-Computer Studies 68, 1-2, 22 40.

DESouzA, C. S. 2005. The Semiotic Engineering of HumanComputer Interaction (Acting with Technology). The MIT Press.

Falcao, T. P., AND PRICE, S. 2009. The role of tangible technologies for promoting effective inclusion. In Proceedings of the Interactive Creative Play with Disabled Children workshop, The 8th International Conference on Interaction Design and Children, Como, Italy, 16-19.

Feeley, K. M., And Jones, E. A. 2008. Preventing challenging behaviours in children with down syndrome: Attention to early developing repertoires. Down Syndrome Research and Practice $1,12,11-14$.

Feng, J., Lazar, J., Kumin, L., And OzoK, A. 2008. Computer usage by young individuals with down syndrome: an exploratory study. In Assets '08: Proceedings of the 10th international ACM SIGACCESS conference on Computers and accessibility, ACM, New York, NY, USA, 35-42.

Feng, J., Lazar, J., Kumin, L., And OzoK, A. 2010. Computer usage by children with down syndrome: Challenges and future research. ACM Trans. Access. Comput. 2, 3, 1-44.

GoH, D. H., ANG, R. P., AND TAN, H. C. 2008. Strategies for designing effective psychotherapeutic gaming interventions for 
children and adolescents. Comput. Hum. Behav. 24, 5, 22172235 .

Hanna, L., Risden, K., And Alexander, K. 1997. Guidelines for usability testing with children. interactions 4, 5, 9-14.

Hung, C.-M., Chiu, C.-H., Chen, Y.-T., Su, M.-J., AND CHEN, H.-S. 2009. Effectiveness of game-based learning of a national health e-learning network for nutrition education in elementary school. In Healthcom'09: Proceedings of the 11th international conference on e-Health networking, applications and services, IEEE Press, Piscataway, NJ, USA, 184-186.

Hung, P.-Y., Lo, J.-L., WANG, H.-Y., CHU, H.-H., AND Hsien, Y.-L. 2009. Cuttinggame: A computer game to assess $\&$ train the visual-motor integration ability for preschool children with autism. In Proceedings of the Interactive Creative Play with Disabled Children workshop, The 8th International Conference on Interaction Design and Children, Como, Italy, 12-15.

HWANG, M., AND WINDSOR, J. 1999. Imitation in the spontaneous language of children with and without down syndrome. Clinical Linguistics and Phonetics 13, 323-334.

Kasari, C., Freeman, S., Mundy, P., and Sigman, M. D. 1995. Attention regulation by children with down-syndrome coordinated joint attention and social referencing looks. American Journal on Mental Retardation, 100, 128-136.

LANDRY, S. H., AND CHAPIESKI, M. L. 1989. Joint attention and infant toy exploration: Effects of down syndrome and prematurity. Child Development, 60, 103-118.

LatAsh, M. 2000. Motor coordination in down syndrome: The role of adaptive changes. Perceptual-Motor Behavior In Down Syndrome, 199-223.

LóPez, G., And Nuevas, J. F. 1997. Perspectives Em La Educación e Integración de los niños con Síndrome de Down. Paids, Barcelona.

NiElsen, M., AND HUdRY, K. 2010. Over-imitation in children with autism and down syndrome. Australian Journal Of Psychology 62, 2, 67-74.

NIELSEN, J., AND MACK, R. L. 1994. Usability Inspection Methods. John Wiley and Sons, Inc.

NiElsen, J. 1993. Usability Engineering. Academic Press Inc, Boston.

Norman, D. A., AND Draper, S. W. 1986. User Centered System Design; New Perspectives on Human-Computer Interaction. L. Erlbaum Associates Inc., Hillsdale, NJ, USA.

Oliveira, E. R., Luz, L. C. S., And Prates, R. O. 2008. Aplicaç ao semi-estruturada do método de inspeç ao semiótica: estudo de caso para o domínio educacional. In $I H C$ '08: Proceedings of the VIII Brazilian Symposium on Human Factors in Computing Systems, Sociedade Brasileira de Computaç ao, Porto Alegre, Brazil, Brazil, 50-59.

PAPAstergiou, M. 2009. Exploring the potential of computer and video games for health and physical education: A literature review. Comput. Educ. 53, 3, 603-622.

Peixoto, D. C. C., Prates, R. O., And Resende, R. F. 2010. Semiotic inspection method in the context of educational simulation games. In SAC '10: Proceedings of the 2010 ACM Symposium on Applied Computing, ACM, New York, NY, USA, 12071212.

PICKARD, B. M. 2009. Music And Down's Syndrome. Master's thesis, Royal Welsh College Of Music and Drama. Down Syndrome Education International.

Prates, R. O., De Souza, C. S., And Barbosa, S. D. J. 2000. Methods and tools: a method for evaluating the communicability of user interfaces. interactions 7, 1, 31-38.

Rondal, J. A., And LAmbert, J. L. 1983. The speech of mentally retarded adults in a dyadic communication situation: Some formal and informative aspects. Psychologica Belgica, 23, 4956.

SATTERFIELD, D. 2009. Designing social and emotional experiences for children with cognitive and developmental disabilities. In Proceedings of the Interactive Creative Play with Disabled Children workshop, The 8th International Conference on Interaction Design and Children, Como, Italy, 16-19.

Savelsbergh, G., Kamp, J. V. D., Ledebt, A., And PlaninSEK, T. 2000. Information-movement coupling in children with down syndrome. In Perceptual-Motor Behavior In Down Syndrome, Human Kinetics, 251-276.

Schopler, E., Reichler, R. J., BAShford, A., LAncing, M. D., AND MARCUS, L. M. 1990. Psychoeducational profile revised. Pep-R.

SchwartzMan, J. S. 1999. Sindrome de Down. Editora Mackenzie, So Paulo.

SMITH, L. 1987. The structure of dialogue in early language development: Longitudinal case studies of down syndrome and nonretarded toddlers. Psychology And Early Development, 201-213.

So, L., AND DodD, B. 1994. Down syndrome and the acquisition of phonology by cantonese-speaking children. Journal of Intellectual Disability Research, 38, 501-517.

Somogyi, E., Kiraly, I., NAdel, J., ANd Gergely, G. 2006. The development of intentional imitation - a comparative study. In The Annual Meeting Of The Xvth Biennial International Conference On Infant Studies.

Technologies, U., $2009 . \quad$ Unity 3d user manual (online). Web Site. Available at: www.unity3d.com/support/documentation/Manual and accessed in september 2009.

TristaO, R. M., And Feitosa, M. A. G. 1998. Linguagem na sndrome de down. Psicologia: Teoria e Pesquisa, 14, 127-137.

Virji-Babul, N., Kerns, K., Zhou, E., Kapur, A., And SHIFFRAR, M. 2006. Perceptual-motor deficits in children with down syndrome: Implications for intervention. Down Syndrome Research And Practice 2, 10, 74-82.

Viva, A. T. M. M. D., ANd Cioni, S. B. G. 2004. Perception of optic-flow motion in down's syndrome patients. Perception 33 ECVP Abstract Supplement.

Watters, C., Oore, S., Shepherd, M., Abouzied, A., Cox, A., Kellar, M., Kharrazi, H., Liu, F., and Otley, A. 2006. Extending the use of games in health care. In HICSS '06: Proceedings of the 39th Annual Hawaii International Conference on System Sciences, IEEE Computer Society, Washington, DC, USA, 88.2.

ZAMAN, B., AND ABEELE, V. V. 2010. Laddering with young children in user experience evaluations: theoretical groundings and a practical case. In IDC '10: Proceedings of the 9th international Conference on interaction Design and Children, ACM, New York, NY, USA, 156-165. 